\title{
Table of treaty provisions
}

\begin{tabular}{|c|c|}
\hline Treaties & $\begin{array}{l}\text { Art } 19(1) \quad \mathbf{1 4 1}-\mathbf{2} \\
\text { Art } 20 \quad \mathbf{3 1}, \mathbf{7 3}, \mathbf{7 4}\end{array}$ \\
\hline Treaty of Rome & Art 20(1) 73 \\
\hline Art 57(2) 95 & Art 2173,74 \\
\hline Art $66 \quad 95$ & Art $22 \quad 73$ \\
\hline Art $118 \quad \mathbf{1 0}$ & Art $23 \quad 73$ \\
\hline Art 118a 200-201 & Art $24 \quad 73$ \\
\hline $\begin{array}{c}\text { Art } 11910,50,51,109-10 \\
111,112-13,117-18,119\end{array}$ & $\begin{array}{l}\text { Part Three Title V } 103 \\
\text { Art } 45 \mathbf{1 1}, \mathbf{3 1}, \mathbf{7 2}-\mathbf{3}, \mathbf{7 4}, \mathbf{7 5}, \mathbf{7 9}, \\
\quad \mathbf{8 2}, \mathbf{8 5}, \mathbf{8 7}, \mathbf{1 7 4}\end{array}$ \\
\hline Treaty of Amsterdam & Art 45(3) $\quad 78$ \\
\hline Art $2 \quad 165$ & $\operatorname{Art} 45(3)(d) \quad 76$ \\
\hline Art $3 \quad \mathbf{1 6 5}$ & Art 45(4) $\mathbf{8 2 , 8 7}$ \\
\hline Art $13 \quad \mathbf{1 1 0}, \mathbf{1 4 1 - 2}$ & Art $46 \mathbf{3 1}, \mathbf{3 4}$ \\
\hline Art $141 \quad \mathbf{1 1 0}, \mathbf{1 1 3}$ & Art $49 \quad \mathbf{1 2}, \mathbf{7 6}, \mathbf{9 9}-\mathbf{1 0 0}, \mathbf{2 5 9}$ \\
\hline Art $141(4) \quad \mathbf{1 2 7}, 128$ & $\begin{array}{ll}\text { Art } 53 & \mathbf{8 6} \\
\text { Art } 54 & \mathbf{2 5 9}\end{array}$ \\
\hline $\begin{array}{l}\text { Treaty on European Union } \\
\quad(T E U)\end{array}$ & $\begin{array}{ll}\text { Art } 56 & \mathbf{3 1}, \mathbf{7 6}, \mathbf{9 3}, \mathbf{9 4}, \mathbf{9 8} \\
\text { Art } 79 & \mathbf{1 0 3}\end{array}$ \\
\hline Art 215,110 & Part Three Title IX $\mathbf{5 , 1 7 , 5 3}$ \\
\hline Art $3 \quad 110$ & 54 \\
\hline Art $5(3) \quad \mathbf{1 7}, 33$ & Art $145 \quad 53$ \\
\hline Art 5(4) 33 & Art 146(1) $\quad 64$ \\
\hline Art 6(2) 23 & $\begin{array}{l}\text { Art } 148 \mathbf{5 4} \\
\text { Art } 148(1) \quad \mathbf{5 4}\end{array}$ \\
\hline Treaty on the Functioning of the & Art 148(2) $\mathbf{5 4}$ \\
\hline European Union (TFEU) & Art 148(3) $\mathbf{5 5}$ \\
\hline Art $2 \quad 30,31$ & Art 148(4) $\mathbf{5 5}$ \\
\hline Art 2(2) $\quad 17$ & Art 148(5) $\mathbf{5 5}$ \\
\hline Art 2(3) 53 & Part Three Title X $\mathbf{5 , 1 7 , 5 3}$ \\
\hline Art $4 \mathbf{1 7}, \mathbf{3 0}, \mathbf{3 1}$ & Art $149 \quad \mathbf{5 5}$ \\
\hline Art 5(2) $\mathbf{1 7 ,} \mathbf{2 9}$ & Art $150 \quad \mathbf{5 4}$ \\
\hline Art $18 \mathbf{3 1}, \mathbf{7 3}, \mathbf{1 4 4}$ & Art $151 \quad \mathbf{3 0}, \mathbf{3 2}$ \\
\hline Art $19 \mathbf{3 1}, \mathbf{3 4}, \mathbf{1 1 0}, \mathbf{1 4 4}$ & Art $152 \quad \mathbf{4 ,}, 38$ \\
\hline
\end{tabular}


Art 153 5, 18, 29, 30, 33, 34, 37, 200

Art 153(1) 31

Art 153(1)(c) 33, 34

Art 153(1)(d) 33, 34

Art 153(1)(e) 18, 32

Art 153(1)(f) 18, 32, 33, 34

Art 153(1)(g) 33, 34

Art 153(1)(i) 31

Art 153(2)(b) 32

Art 153(3) $\quad 40$

Art 153(4) 34

Art 153(5) 31, 219, 254

Art 154 4, 34, 35

Art 154(2) 34

Art 154(3) 34

Art 154(4) 36

Art 155 4, 206

Art 155(1) 35

Art 155(2) 35

Art 157 31, 34, 50, 110, 113,

$117-18,120,174,183$

Art 157(2) $\quad \mathbf{1 1 8}$

Art 157(3) 31

Art 157(4) $\mathbf{1 2 7}$

Art $258 \quad \mathbf{5 , 4 7 , 4 8}$

Art $259 \quad \mathbf{5}$

Art $260 \quad 5,47$

Art $261 \quad 5$

Art $267 \quad 46$

Art 288 4, 18, 39

Art 29433

\section{Protocols}

Protocol No 2 on the application of the principles of subsidiarity and

proportionality 17,33

Protocol No 21 on the position of the United Kingdom and Ireland in respect of the area of freedom, security and justice 103

Protocol No 22 on the position of Denmark 103

European Convention on Human

Rights (ECHR) 21, 22,

23-4, 139-40, 267-8

Art $9 \quad 147$

Art $11 \quad \mathbf{1 0 2}$

European Social Charter

24

Art 1(3) 22

EU Charter of Fundamental

Rights 16, 20, 21-4, 100,

111, 267

Art 15(2) 23

Art $16 \quad 23$

Art $17 \quad 23$

Art 21 111, 155

Art 21(1) 141, 144

Art 21(2) 144

Art 23111

Art $28 \quad 92$

Art $29 \quad \mathbf{2 2}$

Art $30 \quad 22$

Art 31(1) $\quad 202$

Art 31(2) $\quad 202$

Art 33(2) 132, 137

Art 51(1) 21 